\title{
The gravitational search algorithm for incorporating TCSC devices into the system for optimum power flow
}

\author{
Dunya Sh. Wais, Wafaa S. Majeed \\ Department of Electrical Engineering, Al-Mustansiriayah University, Baghdad, Iraq
}

\begin{tabular}{l}
\hline \hline Article Info \\
\hline Article history: \\
Received Jan 14, 2021 \\
Revised Apr 15, 2021 \\
Accepted Apr 26, 2021 \\
\hline
\end{tabular}

\section{Keywords:}

Gravitational search algorithm the thyristor-controlled series compensator Multi-objective Optimal power flow

\begin{abstract}
This paper proposes a gravitational search algorithm (GSA) to allocate the thyristor-controlled series compensator (TCSC) incorporation with the issue of reactive power management. The aim of using TCSC units in this study is to minimize active and reactive power losses. Reserve beyond the thermal border, enhance the voltage profile and increase transmission-lines flow while continuing the whole generation cost of the system a little increase compared with its single goal base case. The optimal power flow (OPF) described is a consideration for finding the best size and location of the TCSCs devices seeing techno-economic subjects for minimizing fuel cost of generation units and the costs of installing TCSCs devices. The GSA algorithm's high ability in solving the proposed multi-objective problem is tested on two 9 and 30 bus test systems. For each test system, four case studies are considered to represent both normal and emergency operating conditions. The proposed GSA method's simulation results show that GSA offers a practical and robust high-quality solution for the problem and improves system performance.
\end{abstract}

This is an open access article under the CC BY-SA license.

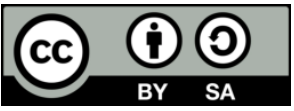

\section{Corresponding Author:}

Dunya Sh. Wais

Department of Electrical Engineering

Al-Mustansiriayah University

Baghdad, Iraq

Email: eema2020@uomustansiriyah.edu.iq

\section{INTRODUCTION}

Nowadays, power systems have severe problems with increasing demand and marketing. The unusual operation of power systems would overload the lines, decrease the buses' voltage, and the generator units will not provide the system with reactive power. However, to solve the problem, three solutions such as increasing power generation, construct new transmission lines, and installing flexible alternating current transmission systems (FACTS) units can be applied. Establishing new power generation units to increase power generation and erected new transmission lines is not practical because of economic and ecological restrictions. Therefore, optimal reactive power flow management is essential for the economic and secure operation of power systems and could improve system performance. Results minimize power losses, decrease reactive power generation, increase reactive power reserve, and voltage profile improvement [1], [2].

The thyristor-controlled series compensator (TCSC) is a common FACTS known for its quick response and least expensive. Therefore, choosing the best size and location of TCSC devices is essential for improving modern power systems' performance [3]. Heuristic algorithms can optimize various convex and non-convex problems by generating random numbers without considering the problem's complexity and constraints [4]. Thus, different intelligent techniques, including differential evolution [5], [6], seeker optimization algorithm [7], Jaya algorithm [8], gravitational search algorithm [9], particle swarm 
optimization [10]-[12], bacteria foraging algorithm [13], exchange market algorithm [14], biogeography based optimization [15], shuffle frog leaping algorithm [16] and harmony search algorithm [17] have been proposed to solve OPF problem successfully.

One of the most powerful optimization algorithms is a gravitational search algorithm. In the resolution of various optimization problems, the gravitational search algorithm (GSA) has been evaluated for high-quality performance. Therefore, GSA is used in many papers for solving various complex and nonconvex problems recently [18], [19]. GSA algorithm is categorized as a physics-based algorithm depending on the law of gravity and mass interactions. The GSA method's operating principle is based on Newtonian gravity laws and the laws of motion [20].

In this paper, the GSA method allocates TCSC devices into transmission systems formulated as a nonlinear optimization problem with equality and inequality limitations to ensure the power system's effective technical and economic operation. This paper's multi-objective function includes reducing active and reactive power losses, improving voltage profile, reducing the cost and number of TCSC units in nominal and contingency operations. The proposed method's performance is experienced on the standard IEEE 9-bus and 30-bus test systems. Attained results have been compared with other methods and demonstrate that the proposed method provides very remarkable results for solving this problem. The rest of the paper is organized is being as: section 2 defines Thyristor-controlled series compensator modeling into the power system. Section 3 describes the mathematical formulation of the problem, and in section 4, the proposed GSA algorithm is offered. Section 5 provides the obtained results of the simulation is compared to other methods. Finally, the conclusion of the application of the proposed GSA method is shown in section 6.

\section{THYRISTOR-CONTROLLED SERIES COMPENSATOR}

TCSC is one of the essential members of the FACTS family that is increasingly applied to H.V. long transmission lines in the modern power system implemented for series compensation. It can have various roles in the power system's operation and control, such as scheduling power flow. Decreasing unsymmetrical components; reducing net loss; providing voltage support; limiting short-circuit current; mitigating subsynchronous resonance (SSR); damping the power oscillation; enhancing transient stability [21].

TCSC has many advantages like low cost, fast response, and good performance [22]. TCSC has two capacitive and inductive operation modes; hence, transmission lines' reactance can be increased or decreased to the TCSC mode. Many articles discussed the modeling of TCSC. In [23], the TCSC model is considered as three parallel-connected switches. In this model, to prevent resonance, only one element is connected, whereas the two other aspects are disconnected, and the reactance value of TCSC $\left(x_{T C S C}\right)$ is considered as a function of transmission-line reactance $\left(x_{T . L}\right)$ [24]. To avoid overcompensation of the transmission line, the value of $\left(x_{T . L}\right)$ can be calculated by (1):

$$
-0.8 x_{T \cdot L} \leq x_{T C S C} \leq 0.2 x_{T \cdot L}
$$

In references [25], [26], the value of $x_{T C S C}$ Varies from one application to another and is constrained by (2) and (3). Figure 1 shows the modeling of TCSC in the transmission line.

$$
\begin{aligned}
& -0.7 x_{T \cdot L} \leq x_{T C S C} \leq 0.3 x_{T \cdot L} \\
& -0.5 x_{T \cdot L} \leq x_{T C S C} \leq 0.5 x_{T \cdot L}
\end{aligned}
$$

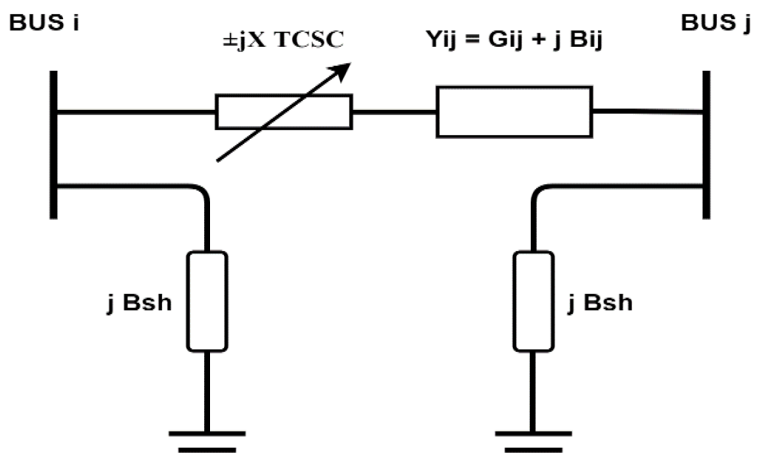

Figure 1. The modeling of TCSC in a power transmission line [5] 
The location of TCSC devices is limited. In addition to lines connecting to two generation buses, TCSC devices should be mounted on all transmission lines. Therefore, they cannot be sequenced with the transformers and can not be used in light-loaded systems [27].

\section{PROBLEM FORMULATION}

This paper aims to find the problem's optimal values using a multi-objective OPF problem that considers TCSC devices' existence. The goal of this study is to obtain additional economic and technological assistance. There are several control variables in the OPF issue with the TCSC unit. The active output power of the generation systems and the positions and sizing of the TCSC components are thought control variables. And the GSA parameters and weighting factors (W1: $W 5)$. In the proposed problem, the objective function's terms are active power generation cost, TCSC operation cost, active and reactive power losses, voltage profile, and number of TCSCs. The objective function can be expressed as:

$$
\operatorname{Min}(\mathrm{obj})=\sum_{i=1}^{N G} f i\left(P G_{i}\right)+W 1 \times P_{\text {losses }}+W 2 \times\left|Q_{\text {losses }}\right|+W 3 \times V D+W 4 \times \text { cost }+W 5 \times N T
$$

The weighting factors $w_{i}$ for the $i^{\text {th }}$ the objective function, which discloses the comparative rank between the $m$ objectives. $w_{i}$ it is constant to each test system and the case under study, and its random value $\in[0,1] ; P G_{i}$ The generated power in (MW) at bus $i$ and $N T$ is the number of TCSC units. In (5) is used to calculate the total fuel cost of generation units:

$$
\sum_{i=1}^{N G} f i\left(P G_{i}\right)=\sum_{i=1}^{N G} a i+b i \times P G_{i}+c i \times P G_{i}^{2}
$$

where $N G$ is the number of generation unit, $a i, b i$, and $c i$ shows cost coefficients of $i^{\text {th }}$ generator. One of the goals of (4) is to reduce the active and reactive power losses that are a function of the magnitude of the bus's voltage $\left(V_{i}, V_{j}\right)$, mutual conductance and susceptance $\left(G_{i j}, B_{i j}\right)$, and the phase difference $\left(\theta_{i j}\right)$ between the voltages of buses $i$ and $j$ for the total number of buses $N B$ :

$$
\begin{aligned}
P_{\text {losses }} & =\sum_{i, j \in N B} G_{i j}\left(V_{i}^{2}+V_{j}^{2}-2 V_{i} V_{j} \cos \theta_{i j}\right) \\
Q_{\text {losses }} & =\sum_{i, j \in N B} B_{i j}\left(V_{i}^{2}+V_{j}^{2}-2 V_{i} V_{j} \sin \theta_{i j}\right)
\end{aligned}
$$
using (8):

Another objective in (4) is to enhance the voltage profile by minimizing the buses voltage deviations

$$
V D=\sum_{i=1}^{N B}\left|V_{i}-V_{r e f}\right|
$$

where $V_{i}$ is the voltage in bus $i$ and $V_{\text {ref }}$ It is the reference voltage. Due to the high cost of TCSC devices in the power system, it is essential to reduce this objective function cost. The cost can be calculated according to (9-10) [28]:

$$
\begin{aligned}
& C_{T C S C}=0.0015 \times S_{T C S C}^{2}-0.713 \times S_{T C S C}+153.75 \\
& \text { Cost }=C_{T C S C} \times S_{T C S C}
\end{aligned}
$$

here, Cost is the TCSC's whole investment in line, $C_{T C S C}$ is each TCSC's operating cost coefficient in $\$$ MVAr and $S_{T C S C}$ is the installed capacity of TCSC in MVAr (Mega Volt-Amperes reactive) that can be calculated by (11):

$$
S_{T C S C}=I_{\text {Lmax }}^{2} \times x_{T C S C}
$$

where $I_{\text {Lmax }}$ It is the nominal current of the TCSC transmission line. It is preferred to reduce the number of TCSC units ( NT ) in objective function due to enhancing the system's performance through a few FACTS devices to enable control and maintenance. In (4), the main goal is to limit the equality and inequalities of the power system is as: 


\subsection{Total power balance active and reactive}

The power equality constraint should balance supply and demand. Total generated active/reactive power should be equal to total system demand plus power losses which can be evaluated by (12-13):

$$
\begin{aligned}
& \sum_{i=1}^{N G} P G_{i}=\sum_{i=1}^{N B} P D_{i}+P_{\text {losses }} \\
& \sum_{i=1}^{N G} Q G_{i}=\sum_{i=1}^{N B} Q D_{i}+Q_{\text {losses }}
\end{aligned}
$$

where $P G_{i}$ and $Q G_{i}$ are active and reactive power generation in unit $i$, respectively. $P D_{i}$ and $Q D_{i}$ Are active/ reactive power load at bus $i$.

\subsection{Active/reactive power balance at each bus}

Each bus can be modeled on the active and reactive power balance as shown in (14-15):

$$
\begin{aligned}
& P G_{i}=P D_{i}+\sum_{i=1}^{N c l} P F_{i j} \\
& Q G_{i}=Q D_{i}+\sum_{J=1}^{N c l} Q F_{i j} \quad \forall i \in N B, i \neq j
\end{aligned}
$$

where $P F_{i j}$ and $Q F_{i j}$ Are the active and reactive power flow in lines connected to buses $i(\mathrm{Ncl})$, respectively.

\subsection{Power inequality constraints and voltage generation limits}

The lower and the higher limits of the generator voltage, the active and reactive power should be constrained as shown in (16)-(18):

$$
\begin{gathered}
P G_{i}^{\text {min }} \leq P G_{i} \leq P G_{i}^{\text {max }} \\
Q G_{i}^{\text {min }} \leq Q G_{i} \leq Q G_{i}^{\text {max }} \\
V G_{i}^{\text {min }} \leq V G_{i} \leq V G_{i}^{\text {max }}
\end{gathered}
$$

here $G_{i}^{\max }, P G_{i}^{\min }, Q G_{i}^{\max }$ and $Q G_{i}^{\min }$ Are the maximum and minimum active and reactive generation power at bus $i$, respectively. Also $V G_{i}^{\max }$ and $V G_{i}^{\min }$ Are upper and lower limit of generation voltage at bus.

\subsection{Security constraints}

In this problem to meet security constraints, transmission line loadings $\left(S l_{i}\right)$ should be kept within allowable limits and also voltages at load buses $\left(V L_{i}\right)$ should be constrained by their Upper and lower boundaries according to (19-20):

$$
\begin{aligned}
& S l_{i}^{\min } \leq S l_{i}^{\max } \forall i \in N l \\
& V L_{i}^{\text {min }} \leq V L_{i} \leq V L_{i}^{\max } \forall i \in N B \ni N G
\end{aligned}
$$

where $S l_{i}^{\max }$ and $S l_{i}^{\text {min }}$ are the maximum and minimum transmission line loading at line $i . V L_{i}^{\max }$ and $V L_{i}^{\min }$ Are the maximum and minimum values of the voltage at load bus $i$.

\section{GRAVITATIONAL SEARCH ALGORITHM (GSA)}

The GSA is one of the strong stochastic algorithms for research developed by Rashedi et al. [20]. Based on Newtonian laws of gravity and mass interaction, this optimization algorithm has a great potential to be a breakthrough optimization approach. In the GSA, agents are considered objects, and their masses could measure their performances. In this algorithm, each object signifies a solution (or a portion of a solution) to the problem. The gravitational force attracts all of these objects, and this force may be causing a global acceleration of all objects towards the objects with heavier weights. Since the heavier masses have higher fitness values, they represent the best solution to the problem, and they travel more slowly than the lighter masses, which means unsuitable solutions.

In the proposed algorithm, each mass has four particulars: its position, it is active gravitational mass $\left(M_{a i}\right)$, its inertial mass $\left(M_{i i}\right)$ and passive gravitational mass $\left(M_{p i}\right)$. In solving optimization problems with GSA initially, a system's position is described with $\mathrm{N}$ (dimension of the search space) masses. 


$$
X_{i}=\left(X_{i}^{1}, \ldots, X_{i}^{d}, \ldots X_{i}^{n}\right), \text { for } i=1,2, \ldots, N
$$

Where $n$ is the space dimension of the problem and $X_{i}^{d}$ shows the position of the $i^{\text {th }}$ agent in the $d^{\text {th }}$ dimension. The agents of the solution are initially randomly identified according to Newton's gravity theory; a gravitational force from mass $j$ acts mass $i$ at the time $t$ is specified according to (22):

$$
F_{i j}^{d}(t)=G(t) \frac{M_{i}(t) \times M_{j}(t)}{R_{i j}(t)+\varepsilon}\left(X_{j}^{d}(t)-X_{i}^{d}(t)\right)
$$

where $M_{j}(t)$ is the mass of the object $j, M_{i}(t)$ Is the mass of the object $i, \varepsilon$ a small constant, $G(t)$ the gravitational constant at time $t$ and $R_{i j}(t)$ is the Euclidian distance between $i$ and $j$ objects defined as shown in (23):

$$
R_{i j}(t)=\left\|X_{i}(t), X_{j}(t)\right\|_{2}
$$

The total force acting on the $i^{\text {th }}$ the agent is calculated according to (24):

$$
F_{i}^{d}(t)=\sum_{j \in K \text { best }, j \neq i}^{N} \operatorname{rand}_{j} F_{i j}^{d}(t)
$$

where $\operatorname{rand}_{j}$ It is a random number, and Kbest is the first $k$ agent with the most significant mass and the best fitness value. The law of motion is used specifically to measure the $i^{\text {th }}$ agent's acceleration, at $\mathrm{t}$ time in the $d^{\text {th }}$ dimension, based on Newton's gravitation theory. The law of motion is proportional to the force acting on the agent and inversely proportional to its mass. $a_{i}^{d}(t)$ can be calculated according to equation (25):

$$
a_{i}^{d}(t)=\frac{F_{i}^{d}(t)}{M_{i j}(t)}
$$

Also, the searching technique for this concept can be used to find the next position and next velocity of an agent according to equations (26-27):

$$
\begin{aligned}
& v_{i}^{d}(t+1)=\operatorname{rand}_{i} \times v_{i}^{d}(t)+a_{i}^{d}(t) \\
& x_{i}^{d}(t+1)=x_{i}^{d}(t)+v_{i}^{d}(t+1)
\end{aligned}
$$

where $x_{i}^{d}(t)$ and $v_{i}^{d}(t)$ Are the position and velocity of an agent at $t$ time in $d$ dimension, respectively. rand $_{i}$ A random number between 0 and $1 . G$ is a gravitational constant and is used to control the search accuracy and is initialized randomly at the starting and will decrease with increasing iteration number of programs.

$$
G(t)=G_{0} e^{-\alpha \frac{t}{T}}
$$

Where $\alpha$ is a user-specified constant, $T$ the total number of iterations and $t$ is the current iteration. The masses of the agents are calculated using fitness evaluation. Newton's law of gravity and law of motion refers to a heavy mass that moves slower and has a higher pull on power. In the proposed algorithm, the masses are updated as shown in (29)-(31).

$$
\begin{aligned}
& M_{a i}=M_{p i}=M_{i i}=M_{i}, i=1,2, \ldots, N \\
& m_{i}(t)=\frac{\text { fit }_{i}(t)-\operatorname{Worst}(t)}{\operatorname{best}(t)-\operatorname{Worst}(t)} \\
& M_{i}(t)=\frac{m_{i}(t)}{\sum_{j=1}^{N} m_{j}(t)}
\end{aligned}
$$

Where $f i t_{i}(t)$ Shows the fitness value of the agent $i$ the time, and in each population, the best $(t)$ and Worst $(t)$ offer the most potent. The weakest agent about their fitness route and for a minimization problem is calculated based on (32-33): 


$$
\begin{aligned}
& \operatorname{best}(t)=\min \text { fit }_{j}(t), j \in\{1, \ldots, N\} \\
& \operatorname{Worst}(t)=\max \operatorname{fit}_{j}(t), j \in\{1, \ldots, N\}
\end{aligned}
$$

In solving an optimization problem proposed algorithm, every agent is placed at a certain point of the search space at the beginning of the program, specifying a solution to the problem. Then, according to equations (26) and (27), the agents are updated, and their following positions are computed. Other parameters of the algorithm as constant gravitational $G$, masses $M$ and acceleration $a$ are calculated via equations 28 , 29, 30, 31, and (25) respectively and are updated in each iteration of the program. The OPF problem optimization is accomplished using the GSA by taking the following steps:

- Step 1. Produce initial population Selecting initial values and.

- Step 2. Calculate the value of the fitness function of each agent for the problem.

- $\quad$ Step 3. Update $G(t)$, best $(t)$, worst $(t)$ and $M_{i}(t)$ for $i=1,2, \ldots, N$.

- $\quad$ Step 4. Calculation of the total force in different directions.

- Step 5. Acceleration and velocity calculation.

- Step 6. Updating agents' positions and checking problem limitations.

- $\quad$ Step 7. Jumping to step 2 until the stop criteria are reached (that is, the number of program iteration).

- Step 8. Stop.

\section{RESULTS AND DISCUSSION}

In this paper proposed GSA algorithm is implemented to solve the proposed problem. It tests the proposed GSA method's efficiency and robustness, and it is applied on standard IEEE 9 and 30 bus test systems. All test systems such as line, bus, and generator data and the maximum and minimum limits for the control variables are available [29], [30].

$G$ is set using in (28), where $G_{0}$ is a gravitational constant and is initialized randomly at the starting and will decrease with increasing iteration programs. $\alpha$, and $T$ the total number of iterations limited to 50 for all case studies to reach an optimal solution as seen in Table 1 with the weight factor, which is given the highest priority for minimizing power loss in all studied cases. All these parameters are constant in each case and test system. The program was written in MATLAB 2016 and applied on a $2.63 \mathrm{GHz}$ Pentium IV personal computer. For each case, 50 test runs were performed to solve the problem using the GSA method in solving each case study, the study explains the following four contributions:

- Case of a normal operation via original system data

- $\quad$ Case of critical line outage

- $\quad$ Case of increased load demand at all buses or in a specific bus

- $\quad$ Case of percentage generation outage at a particular generation unit.

Table 1. The List of the parameter values of the GSA algorithm for all cases and test systems

\begin{tabular}{cc}
\hline Parameter & Value \\
\hline Population size & 100 \\
Generations $(T)$ & 50 \\
Gravitational constant $\left(G_{O}\right)$ & 100 \\
User-specified constant $(\alpha)$ & 20 \\
Weight factors & $\mathrm{W} 1=0.8 ; \mathrm{W} 2=0.12 ; \mathrm{W} 3=0.04 ; \mathrm{W} 4=0.02 ; \mathrm{W} 5=0.02$ \\
\hline
\end{tabular}

\subsection{Case 1 with the 9-bus test system}

The first test system is the IEEE 9-bus power system, with nine buses, bus one as a slack bus, buses 2 and 3 as voltage-controlled buses, and the other buses as load buses. In case 1 with normal operation, Table 2 illustrates the results of the IEEE 9-bus system using GSA compared to DE [5] and APSOA [7] methods with and without TCSC. As seen in Table 2, the obtained results by the GSA method are better than APSOA and DE methods, where the GSA method with TCSC devices could provide a $26.51 \%$ decrease in the active power losses from 0.04719 to $0.0352,0.5 \%$ decrease in the reactive power losses from 0.04112 to 0.04090 and $0.13 \%$ reduction in the power generation cost. In contrast, the obtained active and reactive power losses in the presence of TCSC for APSOA are 0.03659 and 0.4108 , respectively. For the DE method, the active and reactive power losses are 0.4093 and 0.4455 , respectively. The obtained results for case 2 , case 3 , and case 4 by the GSA method are compared with the APSOA method's results in Table 3. 
In case 2, line 9 is assumed to be a critical line. It demonstrates highly active and reactive power losses and voltages in comparison to case 1 . As seen from Table 3, TCSC is used by the GSA method, the active power losses have decreased by $20.31 \%$ from 0.0945 to 0.0753 , and reactive power losses are reduced by $47.29 \% 0.765$ to 0.4032 The voltage deviation is reduced to 0.008 ; here, line 8 is nominated for installation TCSC. The obtained active/reactive power losses in the presence of TCSC for the APSOA method are 0.0748 and 0.5551 , respectively. The comparison results of GSA and APSOA show that the GSA method could find minimum reactive power (by 26.8\%), where the APSOA method could find minimum active power losses (by $0.6 \%$ ). The GSA method's obtained results of solving case 3 in comparison APSOA method are present in Table 3.

In case 3, the load is raised equally in all buses by $60 \%$, and as a result, active/reactive power loss and the voltage deviation are increased. Still, the one active/reactive power loss is minimized to a reasonable level compared to case 1 by installing TCSC units (normal operation case). After installing TCSC, the active power losses have reduced $4 \%$ from 0.0892 to 0.0852 , reactive power losses are condensed $34.14 \%$ from 1.3553 to 0.8925 , and the voltage deviation is reduced to 0 . As seen from Table 3 , the obtained active/reactive power losses by the APSOA method after insertion of TCSC are 0.0882 and 1.1014, which shows the high ability of the proposed GSA method over the APSOA. Furthermore, the obtained TCSC cost by the GSA method is lower than the APSOA method.

In case 4 , Line 9 has been switching off, and the generator at bus 2 has a $66.667 \%$ rate outage. The obtained results from the GSA method show line 8 is the best position for the TCSC unit. In this state, the active/reactive power losses have reduced by $26.39 \%$ and $33.16 \%$, respectively. Furthermore, in Table 3, GSA results are compared to the APSOA method [7] in TCSC and without its inclusion in case 4. The results show that the GSA approach performs better in the active/reactive power loss and TCSC cost.

Table 2. The comparison results of GSA with DE and APSOA methods for IEEE 9-bus system (case 1)

\begin{tabular}{ccccccc}
\hline Method & \multicolumn{3}{c}{ Without TCSC } & \multicolumn{3}{c}{ With TCSC } \\
& DE [5] & APSOA [7] & GSA & DE [5] & APSOA [7] & GSA \\
\hline V2(PU) & 1 & 1 & 1 & 1.0211 & 1 & 1 \\
V3(PU) & 1 & 1 & 1 & 1.0227 & 1 & 1 \\
QG1(PU) & 0.2407 & -0.0616 & 0.2490 & 0.2219 & 0.2134 & 0.2504 \\
QG2(PU) & 0.1446 & 0.3229 & 0.1668 & 0.0984 & 0.0765 & 0.1630 \\
QG3(PU) & -0.0365 & -0.0594 & -0.1143 & -0.0432 & -0.0508 & -0.1180 \\
TCSC Location & $\ldots$ & $\ldots$ & $\ldots$ & L7 & L2 & L2 \\
Gen. Cost(\$/h) & $\ldots$ & 5316.1 & 5318.33 & $\ldots$ & 5375.1 & 5311.39 \\
TCSC Cost(\$/h) & $\ldots$ & $\ldots$ & $\ldots$ & $1.184 \times 106$ & $5.316 \times 104$ & $4.688 \times 103$ \\
X Line (PU) & 0.0625 & 0.092 & 0.902 & 0.03125 & 0.0852 & 0.0736 \\
Compensation level (\%) & $\ldots$ & $\ldots$ & $\ldots$ & 50 & 8 & 25 \\
P losses (PU) & 0.0494 & 0.0479 & 0.04719 & 0.04093 & 0.036598 & 0.0352 \\
Q losses (PU) & 0.5122 & 0.4104 & 0.4112 & 0.4455 & 0.4108 & 0.4090 \\
V.D (PU) & 0.0168 & 0.0162 & 0.006 & 0 & 0 & 0 \\
\hline
\end{tabular}

Table 3. The results of GSA optimum solution for cases 2-4 compared to APSOA

\begin{tabular}{|c|c|c|c|c|c|c|c|c|c|c|c|c|}
\hline \multirow{3}{*}{$\begin{array}{c}\text { Cases } \\
\text { Method }\end{array}$} & \multicolumn{4}{|c|}{ Case2 } & \multicolumn{4}{|c|}{ Case3 } & \multicolumn{4}{|c|}{ Case4 } \\
\hline & \multicolumn{2}{|c|}{ Without TCSC } & \multicolumn{2}{|c|}{ With TCSC } & \multicolumn{2}{|c|}{ Without TCSC } & \multicolumn{2}{|c|}{ With TCSC } & \multicolumn{2}{|c|}{$\begin{array}{c}\text { Without } \\
\text { TCSC }\end{array}$} & \multicolumn{2}{|c|}{ With TCSC } \\
\hline & APSOA & GSA & APSOA & GSA & APSOA & GSA & APSOA & GSA & APSOA & GSA & APSOA & GSA \\
\hline QG2(PU) & 0.618 & 0.6938 & 0.4781 & 0.3781 & 0.542 & 0.4862 & 0.585 & 0.357 & 0.902 & 0.8192 & 0.59576 & 0.6426 \\
\hline QG3(PU) & 0.1464 & 0.2458 & 0.0881 & 0.0553 & 0.354 & 0.2622 & 0.349 & 0.1370 & 0.359 & 0.4335 & 0.2217 & 0.4333 \\
\hline TCSC & $\ldots$ & $\ldots$ & L8 & L8 & $\ldots$ & $\ldots$ & L2 & L1 & $\ldots$ & $\ldots$ & L8 & L8 \\
\hline $\begin{array}{l}\text { Reactance } \\
\text { (PU) }\end{array}$ & & & & & & & 5 & & & & & \\
\hline $\begin{array}{l}\text { Compensat } \\
\text { ion level } \\
(\%)\end{array}$ & $\ldots$ & $\ldots$ & 49.69 & 80 & $\ldots$ & $\ldots$ & 50 & 80 & $\ldots$ & $\ldots$ & 50 & 55 \\
\hline Total V. D & 0.0669 & 0.0031 & 0.0038 & 0.008 & 0.005 & 0.006 & 0.00 & 0.00 & 0.1224 & 0.03 & 0.0245 & 0.008 \\
\hline TCSC & $\ldots$ & $\ldots$ & $1.031 \times$ & $1.139 x$ & $\ldots$ & $\ldots$ & $1.083 x$ & $1.483 \times$ & $\ldots$ & $\ldots$ & $1.162 \times$ & $1.139 \times 1$ \\
\hline Cost & & & 105 & 104 & & & 105 & 104 & & & 105 & 05 \\
\hline
\end{tabular}




\subsection{Case 2 with a 30-bus test system}

The second test system is composed of IEEE-30 buses, which represent a six-generation bus system. There is a slack bus on Bus 1 and voltage control buses on Buses 2, 13, 22, 23, and 27. Without transformers, and has 41 lines. Table 4 illustrates the results of the IEEE 30 bus system using GSA compared to DE [5] and APSOA [7] methods with and without TCSC.

Table 4. The comparison results of GSA with DE and APSOA methods for IEEE 30-bus system (case 1)

\begin{tabular}{ccccccc}
\hline Method & \multicolumn{3}{c}{ Without TCSC } & \multicolumn{3}{c}{ With TCSC } \\
& DE [5] & APSOA [7] & GSA & DE [5] & APSOA [7] & GSA \\
\hline QG1(PU) & -0.01 & -0.001 & 0.0374 & 0.1129 & 0.0189 & 0.0232 \\
QG2(PU) & 0.32 & 0.335 & 0.2859 & 0.1096 & 0.3098 & 0.2211 \\
QG22(PU) & 0.3957 & 0.344 & 0.3662 & 0.2889 & 0.3417 & 0.3269 \\
QG27(PU) & 0.1054 & 0.091 & 0.0882 & 0.1644 & 0.0994 & 0.2081 \\
QG23(PU) & 0.0795 & 0.092 & 0.0887 & 0.0873 & 0.0908 & 0.08659 \\
QG13(PU) & 0.1135 & 0.129 & 0.1289 & 0.2355 & 0.1262 & 0.1179 \\
TCSC Location & $\ldots$ & $\ldots$ & $\ldots$ & 16,29 & 1,17 & 31,36 \\
X Line (PU) & $0.14,0.02$ & $0.07,0.26$ & $0.4,0.18$ & $0.7,0.01$ & $0.0803,0.3027$ & $0.021,0.08$ \\
Compensation level (\%) & $\ldots$ & $\ldots$ & $\ldots$ & 50,50 & $17.16,16.42$ & 50,55 \\
TCSC Cost(\$/h) & $\ldots$ & $\ldots$ & $\ldots$ & $2.055 \times 105$ & $2.87 \times 103$ & $4.124 \times 103$ \\
Q losses (PU) & 0.0245 & 0.023 & 0.02490 & 0.0225 & 0.02162 & 0.0215 \\
P losses (PU) & 0.0899 & 0.076 & 0.0811 & 0.0802 & 0.0727 & 0.0706 \\
V.D (PU) & 0.0226 & 0 & 0 & 0.0186 & 0 & 0 \\
\hline
\end{tabular}

As seen from Table 4, the obtained results case 1 normal operation by the GSA method is better than APSOA and DE methods where the GSA method with TCSC devices could provide a $13.65 \%$ reduction in the active power losses from 0.0249 to $0.0215,12.94 \%$ reduction in the reactive power losses from 0.0811 to 130.0706 . The obtained active and reactive power losses in the presence of TCSC for APSOA and DE methods more than GSA. The operation cost of TCSC by the GSA method is less than the DE method, while this value is more than the APSOA algorithm.

Table 5 summarizes emergency cases 2, 3, and 4 compared between GAS and APSOA methods. In case 2 , line 36 is a significant critical line, and it is an outage of service. Consequently, there are significant active/reactive power losses and line 29 overflowing, which is prevented by the maximum limit, as shown in Figure 2. However, after insertion, the TCSC unit's power flow in line 29 is decreased from 30.09 MW to 19.2 MW under the thermal limit of $20 \mathrm{MW}$. As seen from Table 5, when TCSC is used by the GSA method, the active/reactive power losses are decreased from $0.02567,0.08558$ to $0.02553,0.08483$ respectively, here lines 40, 26 are selected for installing TCSC units. The comparison results of GSA and APSOA for case 2 shows that the GSA method could find better active/ reactive power losses and TCSC operation cost over the APSOA [7] process.

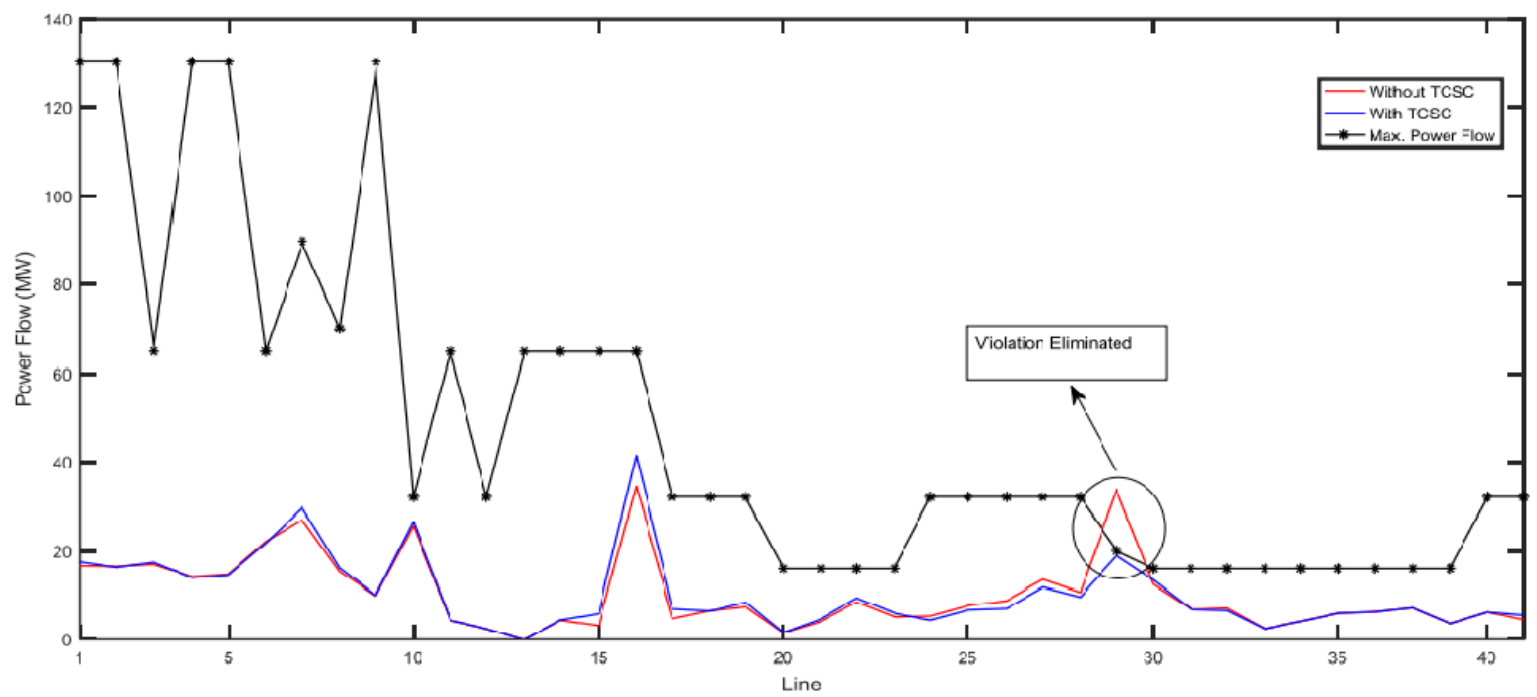

Figure 2. The power flow improvement with GSA case 2 
In the case of 3 , a load of bus eight is increased by $50 \%$, resulting in higher active/reactive power losses and voltage deviation and violation of the power flow in line 29. But after adding the TCSC unit's power flow in line 29 is decreased from $24.03 \mathrm{MW}$ to 19.89 under the thermal limit of $20 \mathrm{MW}$. As seen from Table 4, after connecting TCSC units in case 3., the active/reactive power losses are decreased from 0.03473 , 0.12358 to 0.03017 , and 0.1004 correspondingly, here lines 40,26 are selected for installing TCSC units. The compared results between GSA and APSOA method in Table 5 shows the proposed algorithm could find better active/reactive and TCSC cost over the APSOA method.

In case 3.b, a new load (11 MW+J11 MVAr) is applied at bus 11 that does not achieve good system performance relative to case 1; as shown in Table 5, line 29 has been overflowing. However, with injecting TCSC units in 24, 28 and 40, the active/reactive power losses and voltage deviation reduced from 0.0275 , 0.1115 , and 0.019 to $0.0268,0.10745$, and 0.001 , respectively. As seen from Table 5, after inserting TCSC units obtained active/reactive, the proposed GSA algorithm's voltage deviation and TCSC cost are better than APSOA [7] algorithm.

In case 4 , Generator 2 is having a partial outage (at bus 2) by $40 \%$ is applied. As a result, as seen from Table 5, it causes an increase in the active/reactive power system and causes an overflow in line 29. However, by inserting TCSC units in the lines of 16,17 and 36 , the active power loss, reactive power loss, and voltage deviation successfully decreased from $0.02531,0.08710$, and 0.01 to $0.0228,0.07214$, and 0 , respectively.

Table 5. GSA results were obtained for cases (2-4) compared to APSOA (30-bus system)

\begin{tabular}{|c|c|c|c|c|c|c|c|c|}
\hline \multirow{3}{*}{$\begin{array}{c}\text { Cases } \\
\text { Method }\end{array}$} & \multicolumn{4}{|c|}{ Case2 } & \multicolumn{4}{|c|}{ Case3.a } \\
\hline & \multicolumn{2}{|c|}{ Without TCSC } & \multicolumn{2}{|c|}{ With TCSC } & \multicolumn{2}{|c|}{ Without TCSC } & \multicolumn{2}{|c|}{ With TCSC } \\
\hline & APSOA & GSA & APSOA & GSA & APSOA & GSA & APSOA & GSA \\
\hline QG1(PU) & -0.0644 & 0.0174 & -0.0628 & 0.0172 & -0.06618 & -0.02665 & -0.0301 & -0.04685 \\
\hline QG2(PU) & 0.439 & 0.3374 & 0.3763 & 0.3371 & 0.49175 & 0.4467 & 0.41608 & 0.35401 \\
\hline QG22(PU) & 0.3624 & 0.3346 & 0.3531 & 0.3351 & 0.39533 & 0.4411 & 0.34401 & 0.39797 \\
\hline QG27(PU) & 0.0204 & 0.0701 & 0.01609 & 0.0701 & 0.11886 & 0.0966 & 0.10561 & 0.25974 \\
\hline QG23(PU) & 0.1083 & 0.1215 & 0.081924 & 0.1213 & 0.11208 & 0.1138 & 0.06081 & 0.104763 \\
\hline QG13(PU) & 0.1356 & 0.1193 & 0.11899 & 0.1189 & 0.13533 & 0.01277 & 0.2697 & 0.1091 \\
\hline TCSC Location & $\ldots$ & $\ldots$ & 1,17 & 40,26 & $\ldots$ & $\ldots$ & $1,16,17$ & $26,34,36$ \\
\hline $\begin{array}{l}\text { Line Reactance } \\
\text { (PU) }\end{array}$ & $0.07,0.26$ & $0.2,0.08$ & $\begin{array}{l}0.0803 \\
0.3027\end{array}$ & $0.08,0.07$ & $\begin{array}{c}0.07,0.26 \\
\quad, 0.14\end{array}$ & $\begin{array}{c}0.08,0.38 \\
\quad, 0.4\end{array}$ & $\begin{array}{c}0.0844, \\
0.3444,0.07\end{array}$ & $\begin{array}{c}0.0187 \\
0.2890 \\
0.2390\end{array}$ \\
\hline $\begin{array}{c}\text { Compensation } \\
\text { level (\%) }\end{array}$ & $\ldots$ & $\ldots$ & $17.16,16.42$ & $60,12.5$ & $\cdots$ & $\ldots$ & $\begin{array}{c}20.57 \\
32.46,50\end{array}$ & $\begin{array}{l}76.62,23 \\
94,40.25\end{array}$ \\
\hline TCSC Cost & $\ldots$ & $\ldots$ & $4.404 \times 104$ & $\begin{array}{c}2.78 \times 10 \\
3\end{array}$ & $\cdots$ & $\ldots$ & $6.385 \times 104$ & $\begin{array}{c}6.329 \times 1 \\
03\end{array}$ \\
\hline P Losses (PU) & 0.02978 & 0.02567 & 0.0255 & 0.02553 & 0.0355 & 0.03473 & 0.0303 & 0.03017 \\
\hline Q Losses (PU) & 0.0874 & 0.08558 & 0.0762 & 0.08483 & 0.1212 & 0.12358 & 0.1008 & 0.1004 \\
\hline Total V. D & 0 & 0.01 & 0 & 0 & 0.006 & 0.019 & 0.002 & 0.001 \\
\hline Cases & \multicolumn{4}{|c|}{ Case3.b } & \multicolumn{4}{|c|}{ Case4 } \\
\hline \multirow[t]{2}{*}{ Method } & \multicolumn{2}{|c|}{ Without TCSC } & \multicolumn{2}{|c|}{ With TCSC } & \multicolumn{2}{|c|}{ Without TCSC } & \multicolumn{2}{|c|}{ With TCSC } \\
\hline & APSOA & GSA & APSOA & GSA & APSOA & GSA & APSOA & GSA \\
\hline QG1(PU) & -0.05741 & -0.04633 & -0.05798 & -0.0497 & -0.01374 & -0.09681 & -0.09776 & -0.1183 \\
\hline QG2(PU) & 0.42255 & 0.4308 & 0.38383 & 0.4190 & 0.42432 & 0.4308 & 0.3974 & 0.34122 \\
\hline QG22(PU) & 0.42843 & 0.4600 & 0.38285 & 0.4817 & 0.33054 & 0.3716 & 0.30095 & 0.32328 \\
\hline QG27(PU) & 0.09979 & 0.0940 & 0.0972 & 0.0936 & 0.09326 & 0.1002 & 0.08745 & 0.2498 \\
\hline QG23(PU) & 0.10309 & 0.0638 & 0.03843 & 0.0597 & 0.05765 & 0.07301 & 0.02505 & 0.05372 \\
\hline QG13(PU) & 0.13226 & 0.1333 & 0.2698 & 0.1273 & 0.23677 & 0.1222 & 0.26055 & 0.14211 \\
\hline TCSC Location & & $\ldots$ & $1,16,17$ & $24,28,40$ & $\ldots$ & $\ldots$ & $1,16,17$ & $36,16,17$ \\
\hline $\begin{array}{l}\text { Line Reactance } \\
\text { (PU) }\end{array}$ & $\begin{array}{c}0.07,0.26 \\
0.14\end{array}$ & $\begin{array}{c}0.07,0.15 \\
, 0.2\end{array}$ & $\begin{array}{c}0.0844,0.34 \\
44,0.07\end{array}$ & $\begin{array}{l}0.0823 \\
0.0474 \\
0.0474\end{array}$ & $\begin{array}{c}0.07,0.26 \\
\quad, 0.14\end{array}$ & $\begin{array}{l}0.4,0.14 \\
\quad 0.4\end{array}$ & $\begin{array}{c}0.0844,0.34 \\
44,0.07\end{array}$ & $\begin{array}{c}0.05326, \\
0.07191\end{array}$ \\
\hline $\begin{array}{c}\text { Compensation } \\
\text { level (\%) }\end{array}$ & $\ldots$ & $\ldots$ & $\begin{array}{c}2.57,32.46 \\
50\end{array}$ & $\begin{array}{c}17.5,68.5 \\
, 76.3\end{array}$ & $\cdots$ & $\ldots$ & $\begin{array}{c}20.57,32.46 \\
, 50\end{array}$ & $\begin{array}{l}86.68,48 \\
63,82.02\end{array}$ \\
\hline TCSC Cost & $\ldots$ & $\ldots$ & $\begin{array}{c}7.9812 \times 10 \\
4\end{array}$ & $5.6 \times 103$ & $\ldots$ & $\ldots$ & $4.584 \times 104$ & $\begin{array}{c}1.0627 x \\
104\end{array}$ \\
\hline P Losses (PU) & 0.0292 & 0275 & 0.0269 & 0.0268 & 0.02895 & 0.02531 & 0.025 & 0.0228 \\
\hline Q Losses (PU) & 0.1039 & 0.1115 & 0.0896 & 0.10745 & 0.091 & 0.08710 & 0.0774 & 0.07214 \\
\hline Total V. D & 0.0079 & 0.019 & 0.0057 & 0.001 & 0 & 0.01 & 0 & 0 \\
\hline
\end{tabular}

\section{CONCLUSION}

In this paper, the GSA algorithm is applied for solving optimal power flow problems considering the TCSC devices in 9 and 30 bus test systems. The goal of solving the multi-objective problem was to minimize 
active and reactive power losses, voltage deviation, TCSC cost installation, and the number of TCSC units under normal and abnormal operating situations. The proposed GSA algorithm obtained results are compared with different trusted tools such as DE and APSOA methods. The proposed GSA method achieved the highest power active/reactive loss reduction with minimum generation and TCSC cost. Also, results show that all case studies' voltage profile has improved by reducing the voltage deviation. The proposed GSA method achieved an outstanding level of active/reactive power loss and generation and TCSC cost, especially with other methods.

\section{ACKNOWLEDGEMENTS} University.

This work is supported by, Electrical Department, Faculty of Engineering, Mustansiriyah

\section{REFERENCES}

[1] A. A. Abou El-Ela, A. M. Kinawy, R. A. El-Sehiemy, and M. T. Mouwafi, "Optimal reactive power dispatch using ant colony optimization algorithm,” Electrical Engineering, vol. 93, no. 2, pp. 103-116, 2011, doi: 10.1007/s00202011-0196-4.

[2] L. Rajalakshmi, M. V. Suganyadevi, and S. Parameswari, "Congestion management in a deregulated power system by locating series FACTS devices," International Journal of Computer Applications, vol. 13, no. 8, pp. 19-21, 2011, doi: 10.5120/1801-2404.

[3] N. G. Hingorani and L. Gyugyi, "Understanding FACTS: concepts and technology of flexible AC transmission systems," IEEE Power Engineering Society General Meeting, vol. 2, 2007.

[4] S. Mahapatra, N. Malik, and A. N. Jha, "Cuckoo search algorithm and ant lion optimizer for optimal allocation of TCSC and voltage stability constrained optimal power flow," in International Conference on Intelligent Computing and Smart Communication, Springer, Singapore, 2019, pp. 889-905, doi: 10.1007/978-981-15-0633-8 92.

[5] W. S. Sakr, R. A. El-Sehiemy, and A. M. Azmy, "Optimal allocation of TCSCs by adaptive DE algorithm," IET Generation, Transmission \& Distribution, vol. 10, no. 15, pp. 3844-3854, 2016, doi: 10.1049/it-gtd.2016.0362.

[6] S. Li, W. Gong, L. Wang, X. Yan, and C. Hu, "Optimal power flow using improved adaptive differential evolution," Energy, vol. 198, 2020, Art. no. 117314, doi: 10.1016/j.energy.2020.117314.

[7] M. B. Shafik, H. Chen, G. I. Rashed and R. A. El-Sehiemy, "Adaptive Multi Objective Parallel Seeker Optimization Algorithm for Incorporating TCSC Devices into Optimal Power Flow Framework," in IEEE Access, vol. 7, pp. 36934-36947, 2019, doi: 10.1109/ACCESS.2019.2905266.

[8] Warid, "Optimal power flow using the AMTPG-Jaya algorithm," Applied Soft Computing Journal, vol. 91, 2020, Art. no. 106252, doi: 10.1016/j.asoc.2020.106252.

[9] S. Duman, U. Güvenç, Y. Sönmez, and N. Yörükeren, "Optimal power flow using gravitational search algorithm," Energy Conversion and Management, vol. 59, pp. 86-95, 2012, doi: 0.1016/j.enconman.2012.02.024.

[10] R. P Singh, V. Mukherjee, and S. P Ghoshal, "Particle swarm optimization with an aging leader and challenger's algorithm to solve an optimal power flow problem," Applied Soft Computing, vol. 40, pp. 161-177, 2016, doi: 10.1016/j.asoc.2015.11.027.

[11] J. Zhang, Q. Thang, Y. Chen, and S. Li, "A hybrid particle swarm optimization with small population size to solve the optimal short-term hydro-thermal unit commitment problem," Energy, vol. 109, pp. 765-780, 2016, doi: 10.1016/j.energy.2016.05.057.

[12] E. Naderi, H. Narimani, M. Fathi, and M. R. Narimani, "A novel fuzzy adaptive configuration of particle swarm optimization to solve large-scale optimal reactive power dispatch," Applied Soft Computing, vol. 53, pp. 441-456, 2017, doi: 10.1016/j.asoc.2017.01.012.

[13] A. Panda, M. Tripathy, A. K. Barisal, and T. Prakash, "A modified bacterium foraging based optimal power flow framework for hydro-thermal-wind generation system in the presence of STATCOM," Energy, vol. 124, pp. 720-740, 2017, doi: 10.1016/j.energy.2017.02.090.

[14] Abhishek Rajan and T. Malakar, "Exchange market algorithm based optimum reactive power dispatch," Applied Soft Computing, vol. 43, pp. 320-336, 2016, doi: 10.1016/j.asoc.2016.02.041.

[15] P. K. Roy, "Biogeography-based optimization for multicasting optimal power flow with emission and non-smooth cost function," Expert systems with applications, vol. 37, no. 12, pp. 8221-8228, 2010.

[16] T. Niknam, M. R. Narimani, M. Jabbari, and A. R. Malekpour, "A modified shuffled frog leaping algorithm for multi-objective optimal power flow," Energy, vol. 36, no. 11, pp. 6420-6432, 2011, doi: 10.1016/j.energy.2011.09.027.

[17] M. Abbasi, E. Abbasi, and B. M. Ivatloo, "Single and multi-objective optimal power flow using a new differentialbased harmony search algorithm," Journal of Ambient Intelligence and Humanized Computing, vol. 12, pp. 851-871, 2020, doi: 10.1007/s12652-020-02089-6.

[18] T. A. Khan and S. H. Ling, "An improved gravitational search algorithm for solving an electromagnetic design problemm," Journal of Computational Electronics, vol. 19, pp. 773-779, 2020, doi: 10.1007/s10825-020-01476-8.

[19] S. Jiang, C. Zhang, and S. Chen, "Sequential Hybrid Particle Swarm Optimization and Gravitational Search Algorithm with Dependent Random Coefficients," Mathematical Problems in Engineering, vol. 2020, 2020, doi: $10.1155 / 2020 / 1957812$. 
[20] E. Rashedi, H. Nezamabadi-pour, and S. Saryazdi, "GSA: a gravitational search algorithm, Information Sciences, vol. 179, no. 13, pp. 2232-2248, 2009, doi: 10.1016/j.ins.2009.03.004.

[21] S. Mahapatra and N. Malik, "A hybrid approach for secured optimal power flow and voltage stability with TCSC placement," arXiv preprint arXiv:1701.08951, 2017.

[22] D. Murali, M. Rajaram, and N. Reka, "Comparison of FACTS devices for power system stability enhancement," International Journal of Computer Applications, vol. 8, no. 4, pp. 30-35, 2010, doi: 10.5120/1198-1701.

[23] S. M. R. Slochanal, M. Saravanan and A. C. Devi, "Application of PSO technique to find optimal settings of TCSC for static security enhancement considering installation cost," 2005 International Power Engineering Conference, 2005, pp. 1-394, doi: 10.1109/IPEC.2005.206940.

[24] S. Mahapatra, N. Malik, A. N. Jha, and B. K. Panigrahi, "Voltage Stability Enhancement by IGSA-FA hybrid technique implementation for optimal location of TCSC," Journal of Engineering Science and Technology, vol. 12, no. 9 , pp. $2360-2373,2017$

[25] M. Saravanan, S. M. R. Slochanal, P. Venkatesh, and J. Prince S. Abraham, "Application of particle swarm optimization technique for optimal location of FACTS devices considering the cost of installation and system loadability," Electric Power Systems Research, vol. 77, no. 3, pp. 276-283, 2007, doi: 10.1016/j.epsr.2006.03.006.

[26] G. M. Huang and N. C. Nair, "Incorporating TCSC into the voltage stability constrained OPF formulation," IEEE Power Engineering Society Summer Meeting, 2002, pp. 1547-1552 vol. 3, doi: 10.1109/PESS.2002.1043650.

[27] G. I. Rashed, Y. Sun, and H. I. Shaheen, "Optimal location and parameter setting of TCSC for loss minimization based on differential evolution and genetic algorithm," Physics Procedia, vol. 33, 1864-1878, 2012, doi: 10.1016/j.phpro.2012.05.296.

[28] R. S. Wibowo, N. Yorino, M. Eghbal, Y. Zoka, and Y. Sasaki, "Expected security cost-based FACTS device allocation using hybrid PSO," IEEJ Transactions on Electrical and Electronic Engineering, vol. 6, no. 4, pp. 331-337, 2011, doi: 10.1002/tee.20665.

[29] IEEE Standard Systems Data as an Open-Source MATLAB-Language M-Files, MATPOWER 6. [Online]. Available: http://www.pserc.cornell.edu/matpower/, [Accessed: Feb. 20, 2018].

[30] IEEE Standard Systems Data and Single Line Diagrams, Literature-Based Power Flow Test Cases. [Online]. Available: http://icseg.iti.illinois.edu/power-cases/, [Accessed: Feb. 20, 2018]. 